\title{
Herpamienta multimodal basada en tareas para el aprendizaje del inglés en el grado sexto en Florencia, Caquetá (Colombia)*
}

\author{
Paola Julie Aguilar-Cruz \\ Universidad de la Amazonia e Institución Educativa Jorge Eliécer Gaitán de Florencia, Caquetá, Colombia \\ paolaaguilarcruz@gmail.com
}

\section{RESUMEN}

Este artículo da cuenta de un proceso de investigación-acción educativa, cuyo objetivo fue proponer una herramienta multimodal contextualizada teniendo en cuenta el Aprendizaje Basado en Tareas (TBL, por sus siglas en inglés), con el fin de contribuir al aprendizaje del inglés de un grupo de estudiantes de grado sexto en una institución educativa pública de Florencia, Caquetá. La herramienta se diseñó partiendo del análisis de la revisión documental, de encuestas y de un examen diagnóstico y, para su implementación, se utilizó el diario de campo y evidencia del trabajo de los estudiantes. Los resultados sugieren que el material contextualizado, la multimodalidad y el TBL promueven ambientes efectivos de aprendizaje en los que los estudiantes construyen conocimiento a partir de temas de su interés, de recursos como videos, juegos y plataformas digitales y, además, desarrollan de manera integrada las habilidades del idioma.

Palabras clave: desarrollo de materiales; multimodalidad; Aprendizaje Basado en Tareas.

Cómo citar: Aguilar-Cruz, P. J. (2018). Herramienta multimodal basada en tareas para el aprendizaje del inglés en el grado sexto en Florencia, Caquetá (Colombia). Ciencias Sociales y Educación, 7(14), 65-83. DOI: https:// doi.org/10.22395/csye.v7n14a4

Recibido: 18 de septiembre de 2018.

Aprobado: 14 de noviembre de 2018. 


\section{Multimodal tool Based on Tasks for Learning English in Sixth Grade in Florencia, Caquetá (Colombia)}

\section{ABSTRACT}

This article gives an account of a research-action educational process which main objective was proposing a multimodal context-based tool that based upon Taskbased Learning (TBL) to contribute to the English learning process of a group of students from sixth grade in a public school in Florencia, Caquetá. This tool was designed grounded on document analysis, polls and diagnostic assessments. A field diary and work evidence from the students was used for its implementation. The results suggest that the contextualized resources, the multimodality, and the TBL encourage effective learning environments in which students build their knowledge from their interest topics, fro resources such as video games, games, and digital platforms to develop integrally its language abilities.

Keywords: resources development; multimodality; Task-Based Learning; TBL.

\section{Ferramenta multimodal baseada em tarefas para aprender inglês no sexto ano em Florencia, Caquetá (Colômbia)}

\section{RESUMO}

Este artigo mostra um processo de pesquisa-ação educativa, cujo objetivo foi propor uma ferramenta multimodal contextualizada que considerou a Aprendizagem Baseada em Tarefas (TBL, em inglês), a fim de contribuir para a aprendizagem de inglês de um grupo de estudantes do sexto ano em uma instituição educativa pública de Florencia, Caquetá (Colômbia). A ferramenta foi elaborada a partir da análise da revisão documental, de questionários e de um teste diagnóstico; para sua implantação, foram utilizados o diário de campo e a evidência do trabalho dos estudantes. Os resultados sugerem que o material contextualizado, a multimodalidade e o TBL promovam ambientes efetivos de aprendizagem nos quais os estudantes constroem conhecimento a partir de temas de seu interesse, de recursos como vídeos, jogos e plataformas digitais; além disso, desenvolvem de maneira integrada as habilidades do idioma.

Palavras-chave: desenvolvimento de materiais; multimodalidade; Aprendizagem Baseada em Tarefas (Task-based Learning Approach). 


\section{Introducción}

La elaboración de materiales para la enseñanza del inglés en Colombia ha estado a cargo de editoriales, en su mayoría extranjeras, que abordan contenidos directamente relacionados con los países de origen, lo cual implica una descontextualización y plantea la necesidad de repensar las prácticas de aula y el papel de los materiales. La formación docente es otro factor crucial que influye en el aprendizaje del inglés en el grado sexto (objeto de este estudio), ya que no todos los docentes de primaria tienen formación en esta área, lo cual repercute en las prácticas de aula, haciendo que los estudiantes ingresen a este grado con dificultades en el uso del idioma. Es por esto que algunos docentes e investigadores han decidido diseñar sus propios materiales de enseñanza reconociendo el papel de la multimodalidad en la actualidad y haciendo uso de metodologías acordes al nivel cognitivo y las necesidades de los estudiantes.

Autores como Augusto-Navarro (2015) y Pereira y Ramos (2016) han demostrado la necesidad de contextualizar los contenidos de enseñanza a la realidad de sus países a través de la elaboración de materiales de enseñanza que, además, tienen características multimodales, lo que se constituye en crecimiento profesional para el docente y mejores oportunidades de aprendizaje para los estudiantes. En el contexto colombiano, el Ministerio de Educación Nacional (en adelante, MEN) ha entregado de manera presencial, en algunas instituciones públicas del país, y ha publicado, a través de su página web Colombia Aprende, una serie de recursos de apoyo para enseñar inglés, a saber: El proyecto Bunny Bonita, el programa English for Colombia-ECO, el material pedagógico My ABC English Kit: Supplementary Materials for English Learning and Teaching in primary schools in Colombia, los textos escolares de apoyo para básica secundaria: Way to go para orientar inglés en los grados 6, 7 y 8, e English, please! para orientar inglés en los grados 9,10 y 11 . No obstante, los textos destinados a la básica secundaria no están contextualizados y no incluyen información sobre los procesos y las particularidades del sur del país, lo que invita a reflexionar sobre la pertinencia de este material para ser usado en las diferentes regiones de Colombia. A nivel regional, en el departamento del Caquetá, un grupo de docentes crearon $M y$ English Book como recurso de apoyo para la enseñanza del inglés en primaria con contenidos contextualizados a las temáticas propias de la región, incluyendo climas, actividades de recreación y sitios públicos.

Además de la contextualización, la multimodalidad se convierte en otro factor crucial en el desarrollo de las clases de inglés como lengua extranjera. Estudios de investigadores como Polyxeni y Papadopoulou (2013), Martínez (2013), Martínez y Llorens (2016), al explorar las bondades del uso de recursos multimodales en el aula, encontraron una mejora significativa en la comprensión de textos multimodales, en la motivación y en el proceso de aprendizaje de los 
estudiantes cuando los docentes hacen uso de estrategias y ambientes multimodales. Por su parte, García, García y Hernández (2011), Jiménez (2013), Monsalve, Chaverra y Bolívar (2015), y Rincón y Clavijo-Olarte (2016) encontraron que los estudiantes tienen una preferencia por la lectura de textos multimodales y los consideran significativos, atractivos, motivantes y agradables, y sugieren que estos deben ser usados con mayor frecuencia en el aula porque permiten que los estudiantes exploren más posibilidades para aprender a través de herramientas que pueden encontrar en la web.

Las experiencias de Aldana, Baquero, Rivero y Romero (2012) y Castillo, Insuasty y Jaime (2017) están directamente relacionadas con el desarrollo de materiales de enseñanza, la multimodalidad y el TBL. Aldana et al. (2012) afirman que "los estudiantes y profesores necesitan transformar los procesos de enseñanza y aprendizaje hacia la alfabetización multimodal" (p. 113), es necesario que los docentes enfrenten retos innovadores ante la necesidad de crear clases originales que tengan como base textos multimodales. Por su parte, Castillo et al. (2017) muestran evidencia de que los materiales auténticos y basados en tareas ayudan a los estudiantes a usar el idioma de manera comunicativa y a desarrollar sus competencias gramaticales, textuales e interlocutoras a partir de la evidencia presentada en sus productos escritos y su lenguaje oral, y añaden que las tareas dieron oportunidades a los estudiantes para comunicarse de manera oral y desarrollar diferentes microhabilidades para hablar, leer y escuchar.

En este sentido, se puede afirmar que existe una tendencia hacia la investigación en diseño de materiales, multimodalidad y el TBL que muestra el interés de los investigadores, a nivel educativo, por reorientar el proceso de enseñanza-aprendizaje del inglés.

Este artículo se enfoca en presentar los resultados de un proceso de investigación-acción educativa que se centró en proponer una herramienta multimodal contextualizada a las necesidades de los estudiantes y basada en tareas que contribuyera al proceso de aprendizaje del inglés en el grado sexto en la Institución Educativa Jorge Eliécer Gaitán (en adelante, I. E. JEG) de Florencia, Caquetá partiendo de la pregunta ¿De qué manera una herramienta multimodal contextualizada mediada por el Aprendizaje Basado en Tareas (TBL) contribuye al proceso de aprendizaje del inglés en el grado sexto en la I. E. JEG de Florencia, Caquetá?

\section{Metodología}

La investigación de la que da cuenta este artículo tuvo un enfoque cualitativo que partió de una perspectiva de apoyo y participación (Cresswell, 2009), con una estrategia de investigación desde la investigación-acción educativa (Elliot, 2000), 
utilizando como instrumentos: la revisión documental, el examen diagnóstico, las encuestas, el diario de campo y las evidencias de los estudiantes, siguiendo a Hernández, Fernández y Baptista (2014) en el proceso de investigación-acción como un espiral en cuatro ciclos: diagnóstico de la situación inicial o problemática de la población objeto de estudio, elaboración del plan de acción, implementación y evaluación del plan de acción y retroalimentación, como lo muestra la figura 1.

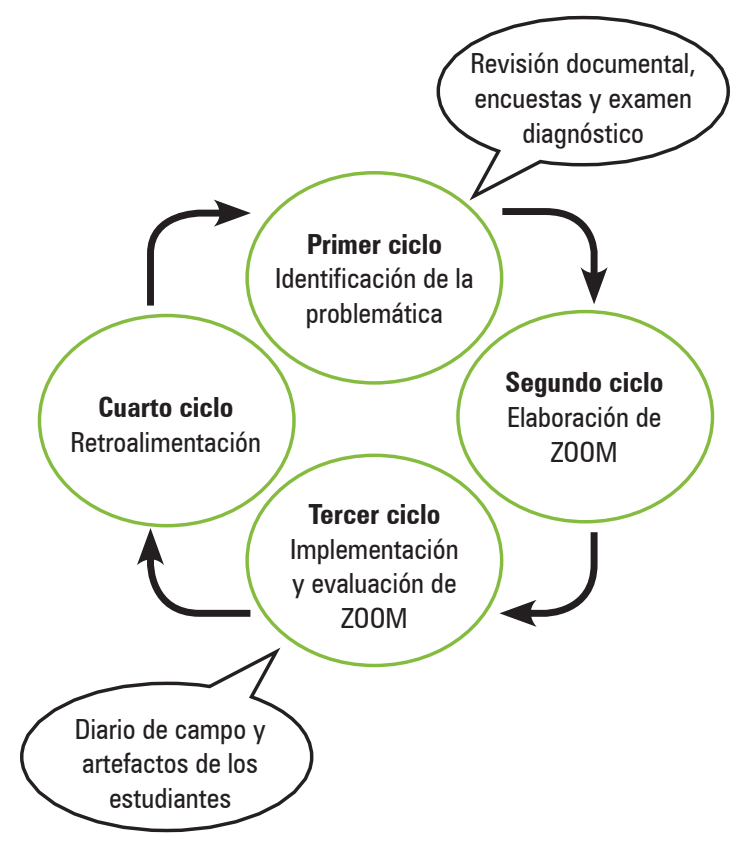

Figura 1. Procedimiento para llevar a cabo la investigación-acción.

Fuente: adaptado de Hernández et al. (2014)

Se diseñó una estrategia de intervención denominada $Z O O M$, que fue una herramienta multimodal basada en tareas cuya elaboración implicó el análisis y triangulación de los resultados de la revisión de documentos como las guías propuestas por el MEN y el plan de estudios de la I. E. JEG, dos encuestas (una a docentes y otra a estudiantes) y un examen diagnóstico al grupo 601 (cuyos resultados evidenciaron un bajo desempeño en el área). Se utilizaron las notas del diario de campo y las evidencias del trabajo de los estudiantes para hacer el análisis de los resultados del proceso de implementación y evaluar la contribución de la estrategia de intervención en el proceso de aprendizaje del inglés, a partir de un proceso de codificación, entendido como el proceso que ayuda a la organización, recuperación e interpretación de los datos (Coffey y Atkinson, 2003), que permitió establecer categorías de análisis. 


\section{Sujetos y contexto}

El grupo 601 fue la población de estudio; estaba compuesto por 42 estudiantes cuyas edades oscilaban entre los 10 y 14 años; 35 de ellos eran antiguos (provenientes de una sede de la I. E. JEG llamada Simón Bolívar) y 7 eran nuevos. La mayoría de familias de estratos 0, 1 y 2 con ingresos familiares mensuales menores a un salario mínimo mensual vigente. Durante el grado quinto no tuvieron docente de inglés con formación en esa área y, en el año 2018, se asignó un docente de lengua castellana para orientar inglés en este curso.

\section{Descripción de la estrategia}

La estrategia de intervención consistió en una herramienta denominada ZOOM (ver figura 2) que plantea la realización de tareas de manera gradual, -parten de lo más básico a lo más complejo-. Se hizo una impresión (CD) con los videos, los audios y una presentación en Power Point y contó con un apoyo digital en una página web de WIX donde se subieron los videos, audios y links con material extra para trabajar durante su implementación, cuyo proceso tuvo una duración de 10 sesiones de trabajo (siete semanas). Debido a que durante su aplicación no hubo disponibilidad continua de recursos (como computadores e internet), algunas sesiones se desarrollaron en el salón de clases y otras en una de las salas de sistemas de la institución. En las tablas 1 y 2 se describen las tareas que se diseñaron e implementaron.

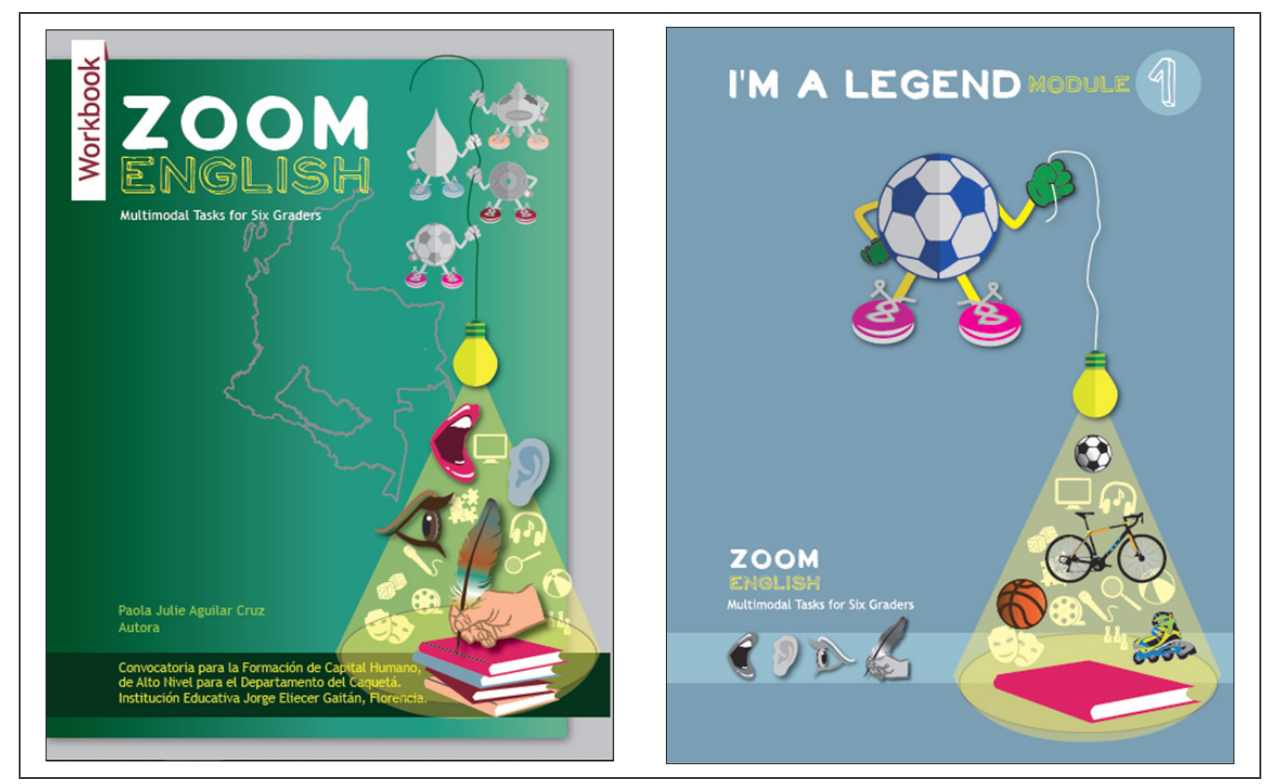

Figura 2. Muestra de la herramienta ZOOM.

Fuente: elaboración propia. 
Tabla 1. Primer conjunto de tareas

\begin{tabular}{|c|c|c|c|c|}
\hline \multirow[b]{2}{*}{ Tipo de tarea } & \multicolumn{4}{|c|}{ Primer conjunto de tareas } \\
\hline & $\begin{array}{c}\text { Nombre de la } \\
\text { tarea }\end{array}$ & Habilidad & Estrategias & Objetivo \\
\hline \multirow{4}{*}{$\begin{array}{l}\text { Antes } \\
\text { (Get ready!) }\end{array}$} & Yes or No? & Habla & $\begin{array}{l}\text { Uso de conoci- } \\
\text { miento previo. }\end{array}$ & \multirow{4}{*}{$\begin{array}{l}\text { - Participar en situaciones } \\
\text { comunicativas. }\end{array}$} \\
\hline & ICs ot IVU: & Hiania & $\begin{array}{l}\text { Hacer inferen- } \\
\text { cias. }\end{array}$ & \\
\hline & There are & Lectura & $\begin{array}{l}\text { Acceso a recur- } \\
\text { sos de informa- } \\
\text { ción. }\end{array}$ & \\
\hline & & & $\begin{array}{l}\text { Uso de conoci- } \\
\text { miento previo. }\end{array}$ & \\
\hline \multirow{4}{*}{$\begin{array}{l}\text { Durante } \\
\text { (Move forward!) }\end{array}$} & $\begin{array}{l}\text { What's the } \\
\text { Word? }\end{array}$ & Escucha & $\begin{array}{l}\text { Identificación de } \\
\text { conceptos princi- } \\
\text { pales y datos re- } \\
\text { levantes. }\end{array}$ & \multirow{4}{*}{$\begin{array}{l}\text { Comprender informa- } \\
\text { ción general de un tex- } \\
\text { to valiéndose de ayudas } \\
\text { como imágenes y pala- } \\
\text { bras clave. }\end{array}$} \\
\hline & & & Uso de cognados. & \\
\hline & $\begin{array}{l}\text { Identifying } \\
\text { words }\end{array}$ & Lectura & $\begin{array}{l}\text { Clasificación de } \\
\text { palabras. }\end{array}$ & \\
\hline & Let's match & Escritura & $\begin{array}{l}\text { Relación de imá- } \\
\text { genes con pala- } \\
\text { bras. }\end{array}$ & \\
\hline $\begin{array}{l}\text { Después } \\
\text { (Let's practice ) }\end{array}$ & True or false? & Lectura & $\begin{array}{l}\text { Comprensión de } \\
\text { lectura. }\end{array}$ & $\begin{array}{l}\text { Responder preguntas } \\
\text { después de escuchar o } \\
\text { leer un texto corto. }\end{array}$ \\
\hline $\begin{array}{l}\text { Producción } \\
\text { (Now I do) }\end{array}$ & Mindmap & Escritura & $\begin{array}{l}\text { Mapeo } \\
\text { Extracción de in- } \\
\text { formación. }\end{array}$ & $\begin{array}{l}\text { Extraer información de } \\
\text { textos y escribirla en for- } \\
\text { matos establecidos. }\end{array}$ \\
\hline
\end{tabular}

Fuente: elaboración propia.

\section{Resultados}

\section{Materiales de enseñanza contextualizados}

De acuerdo con Tomlinson (2003), los materiales son cualquier cosa que pueda ser utilizada para facilitar el aprendizaje de un idioma. Pueden ser lingüísticos, visuales, auditivos o kinestésicos, y se pueden representar de manera impresa, casete, CD o internet. Los materiales de enseñanza, según el autor, deben responder a las necesidades y gustos de los estudiantes. Plantea además que las necesidades y gustos deben ser satisfechas consultando a los implicados en el proceso de enseñanza-aprendizaje antes, durante y después del desarrollo del material. 
Tabla 2. Segundo conjunto de tareas

\begin{tabular}{|c|c|c|c|c|}
\hline \multirow[b]{2}{*}{ Tipo de tarea } & \multicolumn{4}{|c|}{ Segundo conjunto de tareas } \\
\hline & $\begin{array}{c}\text { Nombre de la } \\
\text { tarea }\end{array}$ & Habilidad & Estrategias & Objetivo \\
\hline $\begin{array}{l}\text { Antes } \\
(\text { Get ready!) }\end{array}$ & $\begin{array}{l}\text { What is } \\
\text { necessary } \\
\text { to be an } \\
\text { atlhete? }\end{array}$ & Habla & $\begin{array}{l}\text { Uso de imágenes. } \\
\text { Acceso a recursos de in- } \\
\text { formación. } \\
\text { Uso de plataformas digi- } \\
\text { tales. }\end{array}$ & $\begin{array}{l}\text { Participar en si- } \\
\text { tuaciones comu- } \\
\text { nicativas. }\end{array}$ \\
\hline \multirow{3}{*}{$\begin{array}{l}\text { Durante } \\
\text { (Move } \\
\text { forward!) }\end{array}$} & $\begin{array}{l}\text { Who's the } \\
\text { athlete? }\end{array}$ & Escucha & $\begin{array}{l}\text { Identificación de concep- } \\
\text { tos principales y datos re- } \\
\text { levantes. Uso de platafor- } \\
\text { mas digitales. } \\
\text { Cooperación. }\end{array}$ & \multirow{3}{*}{$\begin{array}{l}\text { Comprender in- } \\
\text { formación ge- } \\
\text { neral de un tex- } \\
\text { to valiéndose de } \\
\text { ayudas comoimá- } \\
\text { genes y palabras } \\
\text { clave. }\end{array}$} \\
\hline & $\begin{array}{l}\text { What sports } \\
\text { do you like? }\end{array}$ & Habla & $\begin{array}{l}\text { Cooperación. } \\
\text { Uso de la expresión cor- } \\
\text { poral. }\end{array}$ & \\
\hline & $\begin{array}{l}\text { Who plays } \\
\text { what? }\end{array}$ & Habla & Cooperación. & \\
\hline \multirow{2}{*}{$\begin{array}{l}\text { Después } \\
\text { (Let's practice) }\end{array}$} & $\begin{array}{l}\text { Choose } \\
\text { the correct } \\
\text { answer }\end{array}$ & Lectura & Comprensión de lectura. & \multirow{2}{*}{$\begin{array}{l}\text { Responder a pre- } \\
\text { guntas después } \\
\text { de escucharoleer } \\
\text { un texto corto. }\end{array}$} \\
\hline & $\begin{array}{l}\text { Memory } \\
\text { Game }\end{array}$ & Habla & $\begin{array}{l}\text { Cooperación. } \\
\text { Uso de conocimiento pre- } \\
\text { vio. }\end{array}$ & \\
\hline $\begin{array}{l}\text { Producción } \\
\text { (Now I do) }\end{array}$ & $\begin{array}{l}\text { Let's } \\
\text { imagine! }\end{array}$ & Escritura & Uso de imaginación. & $\begin{array}{l}\text { Utilizar palabras } \\
\text { familiares y fra- } \\
\text { ses cortas sobre } \\
\text { rutinas en forma- } \\
\text { tos establecidos. }\end{array}$ \\
\hline Tarea final & $\begin{array}{l}\text { Make a } \\
\text { poster }\end{array}$ & Escritura & $\begin{array}{l}\text { Uso de plataformas digi- } \\
\text { tales. }\end{array}$ & $\begin{array}{l}\text { Escribir informa- } \\
\text { ción haciendo uso } \\
\text { de palabras fa- } \\
\text { miliares y frases } \\
\text { cortas. }\end{array}$ \\
\hline
\end{tabular}

Fuente: elaboración propia.

El Ministerio de Educación Nacional (MEN, 2016b) señala que los materiales de enseñanza se deben ver como un apoyo para alcanzar las metas de aprendizaje y no como el currículo en sí. Es por esto que sugieren que los materiales para orientar inglés deben promover el uso de la lengua en contextos donde se integren las cuatro habilidades (escucha, habla, lectura y escritura) en situaciones reales de comunicación, y con actividades significativas para los estudiantes, 
acordes a sus edades y desarrollo cognitivo. Estos materiales deben promover el desarrollo cognitivo, la competencia comunicativa e intercultural. Así, para la escogencia o elaboración de los materiales, el MEN sugiere tener en cuenta la obtención de los objetivos propuestos para los grados, el nivel de la lengua que se usa en el material y si se ajusta o no al nivel lingüístico de los estudiantes, el diseño visual y diagramación, la dificultad de las tareas, el tipo de actividades (si son prácticas y generan motivación), entre otros aspectos .

De acuerdo con Howard y Major (2004), los docentes deberían escoger crear sus propios materiales de enseñanza teniendo en cuenta la contextualización, conocer las necesidades individuales de los estudiantes, la personalización y la puntualidad. Por su parte, Núñez, Pineda y Téllez (2004) dicen que hay cuatro requisitos para diseñar materiales: análisis de necesidades, objetivos, selección y secuencia, actividades de enseñanza y aprendizaje, y la valoración o evaluación. Estos aspectos se tuvieron en cuenta en la elaboración y el diseño de la estrategia de intervención que se describe en este artículo.

Núñez, Téllez y Castellanos (2012) expresan que la innovación es parte fundamental en el desarrollo de materiales y que los materiales que diseñan los docentes se pueden ver como una práctica innovadora en las clases de inglés. Es por esto que la herramienta diseñada se concibe como innovadora al haber sido creada especialmente para el grupo de estudiantes con los que se implementó y, también, partiendo del hecho de que el 90,05 \% de los estudiantes opinaron que la herramienta ZOOM tiene una variedad de tareas de aprendizaje con un diseño atractivo y novedoso. De acuerdo con Núñez et al. (2012), los materiales de enseñanza innovadores enfocados en abordar las necesidades y objetivos de aprendizaje incrementan la atención, la motivación y el aprendizaje efectivo. Durante la implementación de la herramienta se pudo registrar que ZOOM, como material innovador, generó motivación en los estudiantes cuando se evidenciaba cómo estos estaban atentos y motivados durante la clase, como se puede observar en la siguiente nota del diario de campo:

Los estudiantes...demostraban ganas de empezar a trabajar en la tarea propuesta para la clase... demostraron motivación a través de las preguntas que le hacían a la docente: ¿Profe, ya vamos a empezar la actividad de hoy? ¿Qué página de la cartilla vamos a ver hoy? Entre otras.

El componente motivacional juega un papel de suma importancia en la implementación de cualquier estrategia y en el uso de materiales de enseñanza. Howard y Major (2004), expresan que la personalización del material diseñado por docentes promueve la motivación en los estudiantes. La motivación puede ser definida como una fuerza que determina qué tanto se involucran los aprendices en el desarrollo de las tareas y la energía que le dan a ese proceso (Littlewood, 
1998, en Zambrano, Cárdenas e Insuasty, 2011, p. 40). Esa fuerza -que involucró a los estudiantes en el desarrollo de las tareas- se siguió demostrando durante todo el proceso de implementación, tanto que, al finalizar esta fase, el 97,6 \% de los estudiantes manifestaron haberse sentido motivados durante la clase. Otra de las características de la herramienta diseñada fue su contextualización. Según Núñez, Téllez y Castellanos (2017) los materiales desarrollados por docentes se encuentran dentro de la categoría de materiales contextualizados porque se encuentran ligados al contexto, respondiendo a las necesidades locales. En este sentido, $Z O O M$ es un material contextualizado que además contiene actividades con información regional, nacional e internacional, lo que permite abrir la perspectiva de los estudiantes al aprender sobre deportes de su misma región y de otras regiones y países y valorar su propia cultura y la de los demás, lo que se evidenció cuando los estudiantes manifestaron que su parte favorita de la clase fue la que abordaba sus intereses acerca del deporte y los atletas que practican dichos deportes.

Durante la implementación de $Z O O M$ se enfocaron de manera holística las habilidades del inglés: escucha, habla, lectura y escritura. Según Alexander (1967, en Nunan, 1989) se debe entrenar al estudiante en estas cuatro habilidades básicas. Durante la implementación y, en los artefactos de los estudiantes, se evidenció mejoramiento en las cuatro habilidades del inglés al haberse implementado de manera holística estas habilidades a partir de contenido contextualizado.

En la encuesta a docentes de la I. E. JEG, se evidenció que durante sus clases hacen más énfasis en la enseñanza de vocabulario y gramática, pero expresaron que la habilidad que más se debe trabajar en el grado sexto es el habla. Al respecto, el MEN (2016a) sugiere que se debe hacer un seguimiento sistemático a las habilidades para preparar desde lo micro a lo macro, haciendo énfasis en que el trabajo conjunto de las habilidades logra mejores aprendizajes en los estudiantes, además, añaden que es importante que haya un equilibro en la promoción de las habilidades, como se evidenció durante la implementación de $Z O O M$.

Al finalizar la implementación, el 88,1 \% de los estudiantes expresaron que pueden identificar vocabulario nuevo en oraciones sencillas. El 90,05\% dijo que su habilidad oral mejoró ya que pueden pronunciar y usar nuevas palabras. El 71,4 \% expresó que su habilidad lectora mejoró, ya que pueden entender textos cortos de su interés. El 83,3 \% dijo que su habilidad de escritura mejoró porque pueden escribir oraciones cortas y sencillas. El 78,6 \% manifestó que su habilidad de escucha mejoró porque pueden entender a la profesora cuando habla. Finalmente, el 83,3\% dijo que pueden entender y responder a preguntas sencillas. 
Así, se evidencia que los estudiantes mejoraron su conocimiento del idioma al haber aprendido de manera holística las habilidades del mismo, partiendo de contenido contextualizado.

\section{Multimodalidad como eje en el aprendizaje del inglés}

Kress (2010) expresa que la multimodalidad consiste en la combinación de diferentes modos (escritura, imagen, sonido, movimiento, entre otros) para transmitir significados y, además, enfatiza en su papel característico en la comunicación, planteando que esta es multimodal, ya sea por miradas, actos de habla, tacto, etc. En este punto, los estudios sobre alfabetización multimodal, vistos como una práctica social incrustada en la historia y la cultura, en los cuales la mente humana se considera social, y en los que el alfabetismo no se limita solamente a saber leer y escribir (New London Group, 1996), cobran fuerza significativa. De ahí que una herramienta multimodal se conciba como un material de enseñanza que dialoga con características multimodales y del contexto.

En cuanto al diseño de estas herramientas multimodales, Kress (2010) expresa que la escritura por sí sola como único modo de expresar los mensajes no es suficiente y que por eso se hace necesaria la combinación de diferentes modos (como la imagen, el color, la iluminación) que permitan tener beneficios en el proceso de enseñanza y aprendizaje. Esta se da a través del diseño, en el cual se mezclan aspectos como las facilidades, la traducción y la transducción. Según Kress (2010), el diseño es un medio que un individuo tiene para proyectar sus intereses al mundo para tener un efecto en el futuro, y también el proceso por el cual la intención de un diseñador (ya sea un profesor, un orador público, $\mathrm{u}$ otro) se vuelve mensaje.

Para efectos de este artículo, se concibe como multimodalidad la combinación de sonido, imagen y video -entre otros-, en una plataforma (digital o impresa) que sirva como herramienta para el aprendizaje del inglés en el grado sexto, y a partir del cual, como parte del diseño, se reconozca la importancia del contexto y de la cultura de los estudiantes y docentes con quienes se llevó a cabo la estrategia de intervención. Una vez se entiende la importancia de la elaboración de materiales contextualizados para la enseñanza del inglés, se hace necesario entender el papel crucial que juega la multimodalidad en este proceso. ZOOM se caracterizó por tener sus versiones impresa y digital, con una combinación de modos como imagen, texto estático y en movimiento, sonido, color, gráficos como mapas mentales, su página web, entre otros, que le dieron la característica de ser una herramienta multimodal. Farías, Obilinovic y Orrego (2010) y Álvarez (2016) mencionan que las relaciones entre profesores y estudiantes son cada vez más propiciadas por medio de comunicaciones digitales en línea y que las redes sociales le han dado nacimiento a ambientes en línea que generan 
variadas experiencias de aprendizaje, por lo que se hace necesario incorporar en las clases el uso de plataformas digitales.

Durante la implementación, se evidenció que las imágenes, videos y juegos sirven como recurso de aprendizaje. Zambrano et al. (2011) plantean que los juegos pueden ser una herramienta poderosa con la que el docente estimula varios contextos en los que los estudiantes tienen que usar el lenguaje para comunicarse, intercambiar información y expresar sus opiniones. ZOOM es una herramienta enriquecida en imágenes, videos sobre deportes creados y adaptados por la investigadora, presentaciones en Power Point con tareas para realizar en el aula y juegos con preguntas tipo sí o no, verdadero o falso, entrevista, juego de memoria, de unir y de seleccionar imágenes. Según Zambrano et al. (2011), para que los juegos sean efectivos deben ser: interesantes, retadores, motivadores, entretenidos y relevantes, lo que se pudo evidenciar con los juegos de ZOOM. En uno de los juegos, los estudiantes debían encerrar imágenes que respondieran a la pregunta "¿Qué es necesario para ser un atleta?" Cada uno encerró las imágenes que consideraba más precisas para responder a esa pregunta, evidenciándose que no siempre es necesario hacer uso de la oralidad para transmitir significado, sino que también las imágenes apoyan y sirven como recurso de aprendizaje.

Otra tarea consistió en relacionar imágenes con palabras. De acuerdo con Mayer (2001, en Farías et al., 2010) "los estudiantes aprenden mejor con palabras y dibujos que solo con palabras" (p. 59). Con esta tarea se promovió el aprendizaje de vocabulario a través de imágenes que, por su color y forma, llamaron la atención de los estudiantes y les permitió comprender la actividad y garantizar la correcta realización de la tarea.

También se utilizó un juego de memoria diseñado por la investigadora, a través de fichas, el cual tuvo su versión digital, pero no pudo ser aplicado en la sala de informática, por lo que se recurrió a hacer uso de la versión impresa del juego. Consistió en 12 fichas, seis de ellas con la imagen de los deportistas sobre los cuales los estudiantes habían leído en clase, y las otras seis con información que describía a los deportistas. El juego comenzó con todas las tarjetas boca abajo. La idea juego era que los estudiantes pudieran encontrar las parejas dando la vuelta a cada tarjeta y relacionando imagen con texto, hasta encontrar las parejas de tarjetas que coincidían.

Martínez (2013) y Martínez y Llorens (2016) usaron como estrategia imágenes y videos para promover la multimodalidad en el aula, donde encontraron que sus estudiantes se sintieron motivados y atraídos por las mismas, dando como resultado un mejoramiento en el aprendizaje del idioma. Con el ánimo de seguir promoviendo la multimodalidad en el aula, se usaron videos sobre diferentes 
deportes practicados tanto a nivel nacional como internacional, en su mayoría conocidos por los estudiantes. Al finalizar el proceso de implementación, algunos estudiantes opinaron que su parte preferida de la clase fue cuando se hizo uso de videos.

En la fase de indagación, se obtuvo como resultado que una de las actividades más escogidas para implementar en el aula tanto por docentes como por estudiantes eran los juegos y los videos. Después de la implementación, se evidenció que el 88,1 \% de los estudiantes consideran que el tema, las tareas utilizadas y las imágenes fueron interesantes, útiles y significativas para ellos.

Es imperativo en la actualidad ligar la comunicación, la enseñanza y el aprendizaje de los idiomas al mundo digital. Los estudiantes tuvieron la oportunidad de promover su aprendizaje del inglés a través del uso de plataformas digitales para el aprendizaje, donde pudieron compartir sus comentarios y buscar información que necesitaran. El 85,7 \% de los estudiantes opinó que les gustaron los recursos audiovisuales usados por la docente y el 81 \% opinó que les gustó la página web utilizada para las sesiones. Respecto a estas tareas implementadas en plataformas digitales, los estudiantes también opinaron que su parte preferida de las clases había sido las relacionadas con la sala de sistemas porque les permitió explorar y encontrar imágenes.

En una de las tareas implementadas en la sala de sistemas los estudiantes debían buscar imágenes que respondieran la pregunta "¿Qué se necesita para ser un atleta?", una vez encontraban las imágenes que más se ajustaban a lo que querían transmitir, las colocaban en la parte de comentarios de la página $W I X$ y escribían una oración en la cual especificaban qué necesita un atleta para poder serlo. Algunos escribieron que necesitaban ropa, zapatos, un equipo, y otros fueron más profundos en sus comentarios escribiendo que necesitaban estar en buena forma, entrenamiento, buena nutrición, correr, balance, entre otros. En una de las últimas sesiones se realizó la tarea final de la herramienta (Final Task) en la que los estudiantes debían elaborar un póster en una página web -llamada Poster My Wall- plasmando sus conocimientos adquiridos y haciendo uso de la multimodalidad como medio y recurso para transmitir sus ideas, demostrando que con el uso de plataformas digitales se propician espacios de aprendizaje.

\section{Uso del Aprendizaje Basado en Tareas como fomentador de la competencia comunicativa}

El MEN (2016b) plantea que, tanto el enfoque como temáticas son claves para el proceso de evaluación y el logro de metas. A través del Currículo sugerido, el MEN (2016a) recomienda que para el grado sexto se haga uso del Aprendizaje Basado en Tareas porque está de acuerdo con los niveles de desarrollo cognitivo, 
personal y social de los estudiantes de este grado. Ellis (2003) reúne algunas definiciones sobre tareas propuestas por distintos investigadores, de los que vale la pena resaltar a Nunan (1989) quien afirma que:

Una tarea comunicativa es una pieza de trabajo de clase que involucra a los estudiantes en comprender, manipular, producir e interactuar en el idioma objeto de aprendizaje mientras su atención está principalmente enfocada en el significado en vez de en la forma (Ellis, 2003, p. 4).

De acuerdo con Nunan (1991), las tareas tienen cinco componentes: objetivo, input (insumos), actividad, escenario, roles del docente y del estudiante. Estos cinco componentes son parte fundamental de la elaboración de tareas y deben ser la base para la implementación de las mismas en una herramienta multimodal. Por su parte, Ellis (2003) plantea que un plan de clase basado en tareas necesita tres fases importantes: antes de la tarea, durante la tarea y después de la tarea. En la fase antes de la tarea (pre-task) se debe preparar a los estudiantes para desarrollar la tarea; durante la tarea (while-task) se centra en el desarrollo de la tarea, y después de la tarea (post-task) abarca la reflexión sobre cómo fue desarrollada la actividad. La definición de tarea dada por Nunan (1989) fue valiosa para la intervención realizada en cuanto a que se centra en el aspecto comunicativo del inglés, ya que es en el proceso de comunicación donde la multimodalidad adquiere un valor trascendental en la forma en la que los seres humanos se relacionan.

Las tareas de la herramienta multimodal ZOOM estuvieron compuestas por actividades antes (pre-tasks), durante (while-tasks) y después (post-tasks), lo que les daba un orden, una secuencialidad y un propósito en común: alcanzar los mejores conocimientos para desarrollar la tarea final (final task). En este sentido, las tareas partieron de lo más básico hacia lo más complejo, lo que favoreció la realización de las mismas por parte de los estudiantes. De acuerdo con Nunan (1989), las unidades de trabajo deben tener secuencias de tareas coherentes y esa coherencia dependerá de la manera en la que las tareas han sido integradas y secuenciadas. El 81 \% de los estudiantes opinaron que las instrucciones de las tareas de ZOOM fueron claras y fáciles de seguir. El 71,4 \% dijo que el contenido de las tareas fue útil y significativo. El 88,1 \% expresó que la secuencia de las tareas facilitó su proceso de aprendizaje. El 92,9 \% dijo que desarrollar las tareas propuestas ayudó a mejorar su nivel de inglés. Así, se evidencia que, con el TBL, se puede implementar en el aula esa lógica de secuencialidad para lograr mejores aprendizajes.

Ellis (2003) expresa que las tareas llevan consigo procesos cognitivos como "seleccionar, clasificar, ordenar, razonar y evaluar información con el fin de completar la tarea" (p.10). Estos procesos se pueden definir como estrategias 
de aprendizaje que el estudiante usa para comprender mejor la información dada en clase y que varían de estudiante a estudiante. Oxford (1990) define las estrategias como "pasos tomados por los estudiantes para mejorar su propio aprendizaje" (citado por Zambrano et al., 2011, p. 44). De acuerdo con esta autora hay estrategias directas que comprenden las estrategias memorísticas, cognitivas y de compensación, y hay estrategias indirectas que abarcan las metacognitivas, afectivas y sociales. Durante el proceso de implementación se pudo evidenciar el uso de estrategias directas e indirectas por parte de los estudiantes.

En cuanto a las estrategias directas, en una de las primeras tareas se pidió a los estudiantes identificar cognados, es decir, palabras del inglés que se parecen al español, palabras conocidas y desconocidas de un texto sobre deportes. Esta tarea permitió a los estudiantes darse cuenta de qué tanto vocabulario conocían y qué palabras podían identificar por su similitud a su idioma nativo y así comprender mejor la información, lo que ayudó a reforzar las estrategias memorísticas a partir de las cuales se crean conexiones mentales de agrupamiento de palabras para poder comprender la idea de un texto.

Igualmente, los estudiantes hicieron uso de estrategias cognitivas, específicamente la de recombinar el conocimiento que iban adquiriendo, como se evidenció cuando completaban secuencias de oraciones. Ellos también hicieron uso de la estrategia de subrayado para resaltar aspectos que consideraban relevantes de los textos que leían. Los estudiantes hicieron uso de las estrategias de compensación al usar la mímica y la expresión o gestos para darse a entender. Además, hicieron uso de la denominada adivinar inteligentemente, en la que se usan pistas lingüísticas para entender la información.

En cuanto a las estrategias indirectas los estudiantes recurrieron a estrategias metacognitivas relacionadas con la concentración en el aprendizaje. Específicamente, se evidenció uso de la estrategia de prestar atención en clase, lo cual se sustenta cuando los estudiantes estaban atentos a las orientaciones de la docente, además cuando escuchaban los videos y los audios proyectados en el aula. En lo relacionado con las estrategias indirectas, se evidenció el uso, por parte de los estudiantes, de estrategias sociales como hacer preguntas para aclarar o verificar con la docente sus dudas o conocimientos. Algunas de estas eran referentes al significado de palabras, pertinencia en el uso de ciertas imágenes y escritura de oraciones. Los estudiantes también opinaron sobre la secuenciación de las tareas en relación con sus aprendizajes, haciendo uso de la estrategia de autoevaluación y automonitoreo.

El trabajo en equipo también se convirtió en un elemento esencial para el desarrollo y el éxito de algunas tareas. De acuerdo con Smith (1996) cooperar 
significa trabajar en conjunto para lograr objetivos que son compartidos. Los equipos de trabajo fueron escogidos por los mismos estudiantes y además solo fueron organizados para el desarrollo de la clase por lo que se les puede denominar grupos informales. El 78,6 \% de los estudiantes opinaron que pudieron cooperar con sus compañeros para la realización de las tareas y algunos opinaron que su parte favorita de la clase fue cuando se hizo la tarea de la entrevista.

Se encontró que el uso del TBL, con la respectiva secuenciación de las tareas, llevando el orden de menor complejidad a mayor complejidad además de ayudar al desarrollo de estrategias de aprendizaje, fomentó la competencia escritora de los estudiantes. Scott (1996) afirma que la competencia escritura hace referencia a una de las dimensiones del término competencia comunicativa (citado en Ochoa y Medina, 2014). En un comienzo se plantearon tareas donde debían identificar cognados, palabras conocidas y desconocidas para comprender mejor la información, lo que permitió a los estudiantes relacionarse con el vocabulario nuevo y recordar el vocabulario previo. Más adelante, los estudiantes debían completar oraciones obteniendo información de un mapa mental. Esta tarea dio paso a la escritura de oraciones más complejas, haciendo uso del vocabulario que iban comprendiendo. A partir de las diferentes tareas, los estudiantes mejoraron su competencia escritora porque empezaron a construir oraciones cada vez más complejas conforme iban aprendiendo vocabulario y, en una de las últimas tareas, construyeron un párrafo imaginando la rutina de su deportista favorito.

Según el MEN (2016a) "es relevante proponer estrategias didácticas de desarrollo de escritura que acompañen de manera gradual y apropiada el nivel lingüístico, sociolingüístico, y discursivo que sostenga el desarrollo en las otras habilidades" (p.57). En estos párrafos y oraciones escritas por los estudiantes se evidencia el grado de comprensión al que llegaron a través de la forma en la que escribían oraciones en inglés. Además, es notorio su aprendizaje de verbos y vocabulario sobre deportes.

\section{Conclusiones}

A partir de los hallazgos de este trabajo, enmarcado en la investigación-acción educativa, se puede afirmar que elaborar materiales de enseñanza contextualizados permite no solo innovar en el aula sino también crear ambientes efectivos de aprendizaje con los que se promueve la motivación y participación en clase por parte de los estudiantes, ya que se tienen en cuenta asuntos relacionados con su realidad y se promueve el uso de todas las habilidades del inglés para construir conocimiento. También se puede afirmar que es importante hacer uso de la multimodalidad en el aula porque potencializa las habilidades de los estudiantes, permitiéndoles buscar la información necesaria para comunicarse 
en inglés, partiendo del uso de plataformas digitales que les resultan llamativas y que, además, hacen parte de su cotidianidad por fuera del aula.

Adicionalmente, se puede asegurar que el TBL fomenta el uso de estrategias de aprendizaje por parte de los estudiantes, lo que les permite construir el conocimiento de distintas maneras, según sus necesidades y estilos de aprendizaje, además, fomenta el trabajo en equipo que facilita a los estudiantes la exploración de sus conocimientos con ayuda de otros. Al mismo tiempo, se puede decir que mejoran su habilidad para construir oraciones coherentes sobre temas de su interés cuando hay secuencialidad en las tareas.

Teniendo en cuenta los resultados del examen diagnóstico y los resultados de la implementación de la herramienta $Z O O M$, es válido afirmar que se pueden consolidar procesos de aprendizaje efectivos, en los que gracias a la innovación que se genera a partir de la elaboración de materiales, la multimodalidad y el TBL, se puede construir conocimiento y mejorar la competencia comunicativa de los estudiantes de grado sexto.

Aunque la estrategia de intervención presentada en este documento fue beneficiosa para la comunidad objeto de estudio, es claro que se requiere profundizar en otros factores que afectan la manera en la que se desarrollan las clases, como la pobreza y los problemas familiares que de una u otra manera se hacen evidentes en el aula. Igualmente, se debe ahondar y afianzar la implementación de estrategias que faciliten la comprensión de los temas por parte de los estudiantes y se requiere un apoyo mayor en los procesos de enseñanza del inglés en la educación básica, ya que es durante los primeros años que ellos empiezan a relacionarse con el inglés cuando, según el MEN (2016a), hay una latente dificultad para consolidar procesos de formación en lengua extranjera, entre muchas razones, por la poca capacitación que tienen sus docentes, por lo que sería importante plantear los siguientes interrogantes que podrían ser objeto de futuras investigaciones: ¿Cómo fomentar la elaboración de materiales propios para la enseñanza del inglés? ¿Cómo garantizar la continuidad de los buenos procesos de enseñanza y aprendizaje del inglés de un grado a otro y de un ciclo de educación a otro? ¿De qué manera se puede contribuir al fortalecimiento de los procesos de enseñanza y aprendizaje del inglés en la básica primaria? ¿Cuál es el papel de la multimodalidad en el desarrollo de la competencia comunicativa en inglés en la básica primaria?

\section{Referencias}

Augusto-Navarro, E. (2015). The design of Teaching Materials as a Tool in EFL Teacher Education: Experiences of a Brazilian Teaching Education Program. Ilha do Desterro, 68(1), 121-137. doi: http:// dx.doi.org/10.5007/2175-8026.2015v68n1p121 
Álvarez, J. (2016). Meaning making and communication in the multimodal age: ideas for language teachers. Colombian Applied Linguistics Journal, 18(1), 98-115.

Aldana, Y., Baquero, M., Rivero, G., y Romero, D. (2012). Applying Connectivist Principles and the TaskBased Approach to the Design of a Multimodal Didactic Unit. HOW, 19(1), 93-122.

Castillo Losada, C. A., Insuasty, E. A., y Jaime Osorio, M. F. (2017). The impact of authentic materials and tasks on students' communicative competence at a Colombian language school. Profile Issues in Teachers' Professional Development, 19(1), 89-104. doi: http://dx.doi.org/10.15446/profile.v19n1.56763

Coffey, A., y Atkinson, P. (2003). Encontrar el sentido a los datos cualitativos: estrategias complementarias de investigación. Medellín: Universidad de Antioquia.

Cresswell, J. (2009). Research Design. Qualitative, Quantitative, and Mixed Methods. Los Ángeles: University of Nebraska-Lincoln.

Elliot, J. (2000). La investigación-acción en educación. Madrid: Morata.

Ellis, R. (2003). Task-based Language Learning and Teaching. Nueva York: Oxford University Press.

Farías, M., Obilinovic, K., y Orrego, R. (2010). Modelos de aprendizaje multimodal y enseñanza-aprendizaje de lenguas extranjeras. UT. Revista de Ciències de l'Educació, 55-74.

García, D., García, J., y Hernández, Y. (2011). Students' beliefs: Multimodal Texts as Pedagogical Tools in Foreign Language Learning. Revista Papeles, 3(5), 21-35.

Hernández, R., Fernández, C., y Baptista L. (2014). Metodología de la Investigación. Ciudad de México: McGraw-Hill.

Howard, J., y Major , J. (2004). Guidelines for designing effective English language teaching materials. 9th Conference of Pan Pacific Association of Applied Linguistic Conference. 101-109. Recuperado de http://www.paaljapan.org/resources/proceedings/PAAL9/pdf/Howard.pdf

Jiménez, J. (2013). Ayudas en línea para la lectura multimodal en lengua extranjera. Bellaterra Journal of Teaching \& Learning Language \& Literature, 6(2), 69-92.

Kress, G. (2010). Multimodality a Social Semiotic Approach to Contemporary Communication. Londres y Nueva York: Routledge Taylor \& Francis Group.

Martínez, M. (2013). Experiencia de enseñanza multimodal en una clase de idiomas. Ensayos, Revista de la Facultad de Educación de Albacete (28), 1-13.

Martínez, M., y Llorens, E. (2016). Aproximación al uso de recursos multimodales y de las TICs en la enseñanza del inglés. Recuperado de http://hdl.handle.net/10045/58347

Ministerio de Educación Nacional. (2016a). Diseñando una Propuesta de Currículo Sugerido de Inglés para Colombia. Grados $6^{\circ}$ a $11^{\circ}$. English for Diversity and Equity. Recuperado de http://aprende. colombiaaprende.edu.co/sites/default/files/naspublic/Anexo\%2016\%20Dise\%C3\%B10\%20Propuesta\%20\%20Curriculo\%20Sugerido.pdf

Ministerio de Educación Nacional. (2016b). Orientaciones y Principios Pedagógicos. Currículo Sugerido de inglés. Grados $6^{\circ}$ a $11^{\circ}$. English for Diversity and Equity. Recuperado de http://aprende. colombiaaprende.edu.co/sites/default/files/naspublic/Anexo\%2014\%20Orientaciones\%20y\%20 principios\%20Pedagogicos.pdf

Monsalve, M., Chaverra, D., y Bolívar, W. (2015). Caracterización y evaluación de la habilidad de razonabilidad en la producción escrita de textos multimodales. Forma y función, 28(2), 111-133. 
New London Group. (1996). A Pedagogy of Multiliteracies: Designing Social Futures. Harvard Educational Review, 66(1), 60-93.

Nunan, D. (1989). Designing Tasks for the Communicative Classroom. Inglaterra: Cambridge University Press.

Nunan, D. (1991). Language Teaching Methodology. A tetxbook for teachers. Sidney: Prentice Hall.

Núñez , A., Pineda, C., y Téllez, M. (2004). Key Aspects for Developing Your Instructional Materials. Profile, 5(1), 128-139.

Núñez, A., Téllez, M., y Castellanos, J. (2012). A framework for materials development: A path for inservice teachers to build up the instructional design of their research projects. En A. Núñez, M. F. Téllez y J. Castellanos (Eds.), Teacher research on English didactics issues (pp. 17-37). Bogotá: Departamento de Publicaciones Universidad Externado de Colombia.

Núñez, A., Téllez, M., y Castellanos, J. (2017). Materials development for teacher's professional growth. En A. Núñez, M. Téllez, y J. Castellanos (Eds.), Materials for the learning of English and teacher's professional growth (pp. 19-68). Bogotá: Departamento de Publicaciones Universidad Externado de Colombia.

Ochoa, D., y Medina, N. (2013). A Virtual Room to Enhance Writing Skills in the EFL Class. HOW, 21(1), 62-81.

Pereira, H., y Ramos, L. (2016). Diseño de libros de texto para la enseñanza del inglés: una propuesta curricular. Colomb. Appl. Linguist. J., 8(2), 139-150. Recuperado de http://www.redalyc.org/articulo. oa?id=305746478012

Polyxeni, M., y Papadopoulou, M. (2013). Greek Students' Familiarity with Multimodal Texts in EFL. The Internacional Journal of Literacies, 19(1), 37-46. Recuperado de https://cgscholar.com/bookstore/ works/greek-students-familiarity-with-multimodal-texts-in-efl

Rincón, J., y Clavijo-Olarte, A. (2016). Fostering EFL learners' literacies through local inquiry in a multimodal experience. Colombian Applied Linguistic Journal, 18(2), 67-82.

Smith, K. (1996). Cooperative learning: Making "groupwork" work. En C. Bonwell, y T. Sutherlund, ACtive learning: Lessons from practice and emerging issues. New Directions for Teaching and Learning (pp. 71-82). San Francisco, EE.UU: Jossey-Bass.

Tomlinson, B. (2003). Developing Materials for Language Teaching. Trowbridge: Croomwell Press.

Zambrano, L., Cárdenas, M., y Insuasty, E. (2011). Communicative Learning Tasks. Bogotá: Litocentral. 